\title{
Volatile Oxidation Compounds and Stability of Safflower, Sesame and Canola Cold-Pressed Oils as Affected by Thermal and Microwave Treatments
}

\author{
Mustafa Kiralan ${ }^{1}$ and Mohamed Fawzy Ramadan ${ }^{2 *}$ \\ ${ }^{1}$ Department of Food Engineering, Faculty of Engineering and Architecture, Abant Izzet Baysal University, 14280 Bolu, TURKEY \\ ${ }^{2}$ Biochemistry Department, Faculty of Agriculture, Zagazig University, Zagazig 44519, EGYPT
}

\begin{abstract}
The goal of this study was to investigate the effect of heating and microwave treatment on the levels of volatile oxidation products and the stability of safflower (Carthamus tinctorius $\mathbf{L}$.), sesame (Sesamum indicum) and canola (Brassica napus L.) cold-pressed oils. Cold-pressed oils were subjected to conventional heating (oven test) using air-forced oven at $60^{\circ} \mathrm{C}$ and microwave heating for 2 and 4 min. The changes in conjugated diene (CD) and conjugated triene (CT) values were monitored during treatments. As expected, heating generates an increase in $\mathrm{CD}$ and $\mathrm{CT}$ values. The volatile compounds in treated oils were determined using solid phase micro-extraction-gas chromatography/mass spectrometry (SPME-GC/MS). The obtained GC/MS data were used to characterize volatile compounds of cold-pressed oils during heating and microeave treatments. Under oven conditions, 2-heptenal and 2,4-heptadienal isomers were identified as major components in canola oil, while hexanal and 2-heptenal were found in high levels in safflower and sesame oils. Among volatiles, $p$-cymene was the dominant compound found in microwave-treated canola oil. In addition, hexanal and 2-hexenal were found at high amounts upon microwave treatment especially after 4 min of application.
\end{abstract}

Key words: Carthamus tinctorius L., Sesamum indicum, Brassica napus L., Shaal oven test, SPME-GC/MS

\section{Introduction}

Lipid oxidation is a major deterioration problem in oils and fats. Oxidation could alter the flavor of these products by inducing toxic substances and undesirable volatile compounds during oxidation ${ }^{1-3)}$. Hydroperoxides are primary oxidation products which are colorless and odorless. These products are labile and quickly turn into secondary oxidation products such as alkanes, alcohols, aldehydes, and acids $^{4)}$. The volatile compounds of secondary oxidation products have an impact on the lipids flavor at extremely low concentrations. Different volatile oxidation products could be derived from various conditions like heat, light and metal ${ }^{5}$.

Oils and fats was subjected to heating (Schaal oven test) to accelarate thermal oxidation. In this test, lipidic samples are usually heated at $60^{\circ} \mathrm{C}$ in an oven. Hexanal, 2-decenal, 2,4-decadienal, 2-decenal, and pentane were identifed as volatile oxidation compounds by SPME methods in thermally oxidized $\left(\right.$ at $60^{\circ} \mathrm{C}$ ) soybean and corn oils ${ }^{6)}$. In addition, hexanal, pentane, propenal and 2,4-decadienal were identi- fied in high levels in canola oil during heating ${ }^{7)}$.

Microwaves are very popular for high speed and convenience, as compared to conventional heating ${ }^{8)}$. The utilization of microwave in fast food preparation is increased because of its ease of operation, and low cost ${ }^{9}$. Radiation of Microwave penetrates to the food, causing reheating or cooking. However, there are speculations on the ease of free radical formation when fatty foods are exposed to microwave energy resulting in production of objectionable compounds in microwave-cooked foods ${ }^{10)}$. Microwavetreated oils formed reactive free radicals that reacted with the atmospheric oxygen to form hydroperoxides and oxidation products ${ }^{11)}$. Unsaturated lipids and fatty acids are susceptible to oxidation upon microwave radiations which result in losses of their organoleptic and nutritional traits $^{12)}$. Oxidation process increases with increasing microwave power and time. Yoshida and Kajimoto ${ }^{13)}$ studied the stability of sesame oils upon microwave treatment. Limited studies were performed on the volatile oxidation compounds in microwave-treated oils and fats. Aldehydes such

*Correspondence to: Mohamed Fawzy Ramadan, Biochemistry Department, Faculty of Agriculture, Zagazig University, Zagazig 44519, EGYPT

E-mail: hassanienmohamed@yahoo.com

Accepted May 24, 2016 (received for review March 29, 2016)

Journal of Oleo Science ISSN 1345-8957 print / ISSN 1347-3352 online

http://www.jstage.jst.go.jp/browse/jos/ http://mc.manusriptcentral.com/jjocs 


\section{Kiralan and M. F. Ramadan}

as hexaldehyde, phenylacetaldehyde and nonaldehyde were the major volatile oxidation compounds identified in microwave-treated rapeseed oils ${ }^{14)}$.

Recently, cold-pressed oils have gave an increase interest as these edible oils have health-promoting properties. Cold pressing is being considered as an interesting substitute for traditional extraction because of consumers' desire for safe food. Cold pressing is a process that involves no theraml or chemical treatments to extract oil. In addition, cold pressing involves no refining process wherein the recovered lipids may contain a high level of natural antioxidants ${ }^{15-17)}$.

The aim of this study was to investigate the effect of heating and microwave treatment on the levels of volatile oxidation products and the stability of safflower, sesame and canola cold-pressed oils.

\section{Materials and methods \\ 2.1 Materials}

Cold-pressed safflower (Carthamus tinctorius L.), sesame (Sesamum indicum) and canola (Brassica napus L.) oils (without any added antioxidants) were purchased from a local oil producer in Turkey. All other chemicals and solvents were commercially of the highest grade and used without purification. Hexanal, $\alpha$-thujene, limonene, $p$-cymene, $\gamma$-terpinene and nonanal were purchased from Sigma-Aldrich (St Louis, MO, USA).

\subsection{Fatty acid composition of cold pressed oils}

The fatty acid methyl ester(FAME) was prepared according to IUPCA ${ }^{18)}$. The gas chromatograph (GC) analysis of the fatty acid composition was performed using a Shimadzu GC-2010 chromatograph. A DB-23 fused-silica column (30 m, $0.25 \mathrm{~mm}$ i.d., $0.25 \mu \mathrm{m}$ film thickness, Agilent J\&W, USA) was used with helium as a carrier gas at a flow rate of $1 \mathrm{~mL} / \mathrm{min}$. The column temperature was isothermal at $190^{\circ} \mathrm{C}$ wherein the injector and detector temperatures were $230^{\circ} \mathrm{C}$ and $240^{\circ} \mathrm{C}$, respectively. FAME was identified by comparison of their retention times with those of the reference standards.

\subsection{Treatments of cold-pressed oils}

\subsubsection{Thermal treatment (oven test)}

Two samples of each oil $(10 \mathrm{~g})$ were placed in a series of sealed brown glass bottles $(30 \mathrm{~mL})$ and heated for 12 days in a forced-draft air oven at $60^{\circ} \mathrm{C}$. Oxidation was monitored in two day intervals during storage.

\subsubsection{Microwave treatment}

Samples in duplicate $(10 \mathrm{~g})$ were separately divided into a $30 \mathrm{~mL}$ opened brown bottle. Samples were microwavetreated at a constant frequency $(2.450 \mathrm{MHz})$ and a power of $0.45 \mathrm{~kW}$ for two exposure times (2 and $4 \mathrm{~min}$ ). A domestic
Samsung microwave oven(Model MW71E, Malaysia)was used in these experiments. The temperatures pertaining to the oils in the present work were measured after each microwave- application. Temperatures of canola, safflower and sesame oils in the oven reached 115.2, 169.8; 116.5, 171.8 and $129,175^{\circ} \mathrm{C}$ at the two heating periods, respectively.

The volatile compounds as well as conjugated dienes $\left(\mathrm{K}_{232}\right)$ and trienes $\left(\mathrm{K}_{270}\right)$ values were used to follow oxidative changes in the heated and microwave-treated oil samples.

\subsection{Conjugated dienes (CD), and conjugated trienes (CT)}

Coefficients of specific extinction at the absorption wavelengths of 232 and $270 \mathrm{~nm}\left(\mathrm{~K}_{232}\right.$ and $\left.\mathrm{K}_{270}\right)$ were determined according to method Cd 18-90 of the AOCS Official Methods $^{19)}$.

\subsection{Volatile compounds analysis}

Two grams of the sample were placed in $20 \mathrm{~mL}$ headspace screw-top vial and allowed to equilibrate for $15 \mathrm{~min}$ at the constant temperature $\left(35^{\circ} \mathrm{C}\right)$. The headspace was extracted for $45 \mathrm{~min}$ at $35^{\circ} \mathrm{C}$ using a CTC Combi PAL (CTC Analytics AG, Zwingen, Switzerland)autosampler with 75 $\mu \mathrm{m}$ carboxen/polydimethylsiloxane (CAR/PDMS) solid phase micro extraction (SPME) fiber. Volatile compounds were desorbed by inserting the fiber for 10 min into the injection port of gas chromatography kept at $250^{\circ} \mathrm{C}$.

Analysis of volatile compounds was performed with an Agilent model 7890 Series (Agilent Technologies, Santa Clara, CA, U.S.A.) gas chromatographer (GC) in combination with a CTC Combi PAL autosampler and an Agilent $5975 \mathrm{~N}$ mass selective detector (Agilent Technologies, Santa Clara, CA, U.S.A.). The compounds were separated in a capillary column, DB-624 (30 m length $\times 0.25 \mathrm{~mm}$ ID $\times$ $1.4 \mu \mathrm{m}$ film thickness, Agilent Technologies, Santa Clara, CA, U.S.A.) with the following temperature program: $40^{\circ} \mathrm{C}$, hold for $5 \mathrm{~min} ; 3^{\circ} \mathrm{C} / \mathrm{min}$ up to $110^{\circ} \mathrm{C} ; 4^{\circ} \mathrm{C} / \mathrm{min}$ up to $150^{\circ} \mathrm{C}$; $10^{\circ} \mathrm{C} / \mathrm{min}$ up to $210^{\circ} \mathrm{C}$, hold for $12 \mathrm{~min}$. The temperatures for the injection port, ion source, quadrupole, and interface were set at $250^{\circ} \mathrm{C}, 230^{\circ} \mathrm{C}, 150^{\circ} \mathrm{C}$, and $240^{\circ} \mathrm{C}$, respectively. Mass spectra were obtained in the electron impact at $70 \mathrm{eV}$ in full scan and a scan range from m/z 41 to 400 .

Identification of compounds was detected by comparing mass spectra and Kovats index (KI) with the authentic standards and published data, as well as by comparing their mass spectra with the mass spectrometry library of Nist05 (National Institute of Standards and Technology, Gaithersburg MD, U.S.A.) and Wiley 7.0 (Wiley, New York, NY, U.S.A.). KI parameters were calculated using the series of n-hydrocarbons $\left(\mathrm{C}_{4}\right.$ to $\left.\mathrm{C}_{20}\right)$. 


\section{Results and discussion}

\subsection{Fatty acid composition}

Fatty acid composition of cold-pressed oil samples is presented in Table 1. The identified major fatty acids were unsaturated fatty acids, oleic and linoleic acids, ranged with $38.1 \%$ (sesame oil) $-61.7 \%$ (canola oil) and $21.7 \%$ (canola oil)-49.9\% (safflower oil), respectively. Palmitic acid was identified as the major saturated fatty acid and accounted for between $4.78 \%$ (canola oil) and $9.79 \%$ (sesame oil). The results are consistent with the results of Bauer et $a l .^{20)}$ for canola oil, Gecgel et $a l .^{21)}$ for safflower oil, and Uzun et al. ${ }^{22)}$ for sesame oil.

\subsection{Thermal treatment (oven test)}

Conjugated diene (CD) and triene (CT) values are good indicators to follow lipid oxidation. Changes in $\mathrm{K}_{232}$ and $\mathrm{K}_{270}$ values of cold-pressed oils during the storage at $60^{\circ} \mathrm{C}$ are shown in Figs. 1a and b, respectively. As expected, the $K_{232}$ values of the oil samples increased with storage time. The initial values for canola, safflower and sesame oils increased from $0.38,0.24$ and 1.96 to $11.97,35.26$ and 6.21 at the end of storage time. A little increase in CD values of canola and sesame oils observed under oven test condition. However, higher changes occurred in $\mathrm{K}_{232}$ values for safflower oil during storage in comparison to other oils.

CT values of oil samples exhibited an increase trend for canola and safflower oils with storage time. However, a rapid increase observed in sesame oil after 2 days of storage and the $K_{270}$ value of this oil showed stability after that time. The initial $\mathrm{K}_{270}$ value of canola, safflower and sesame oils were $0.16,0.01$ and 0.06 , respectively. After 12 days of storage, CT values for the mentioned oils rise up to 1.06, 1.28 and 1.10, respectively (Fig. 1b).

The initial $K_{232}$ and $K_{270}$ values of cold-pressed canola oil

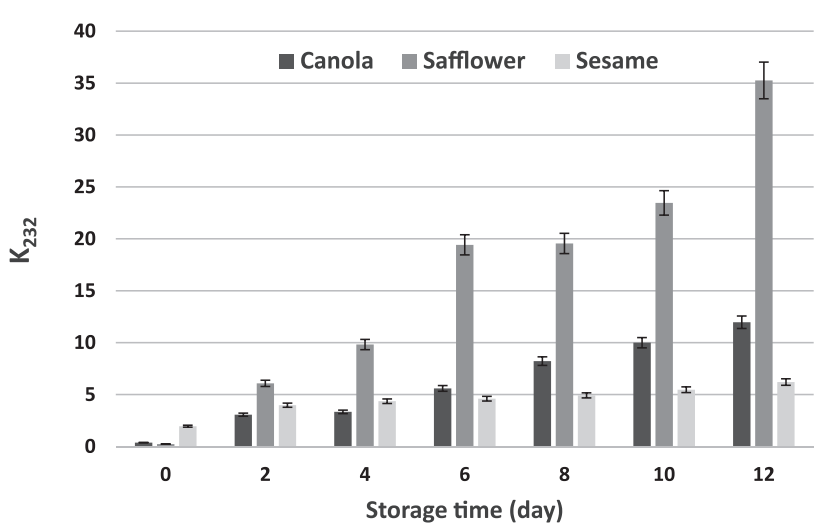

$\mathbf{A}$

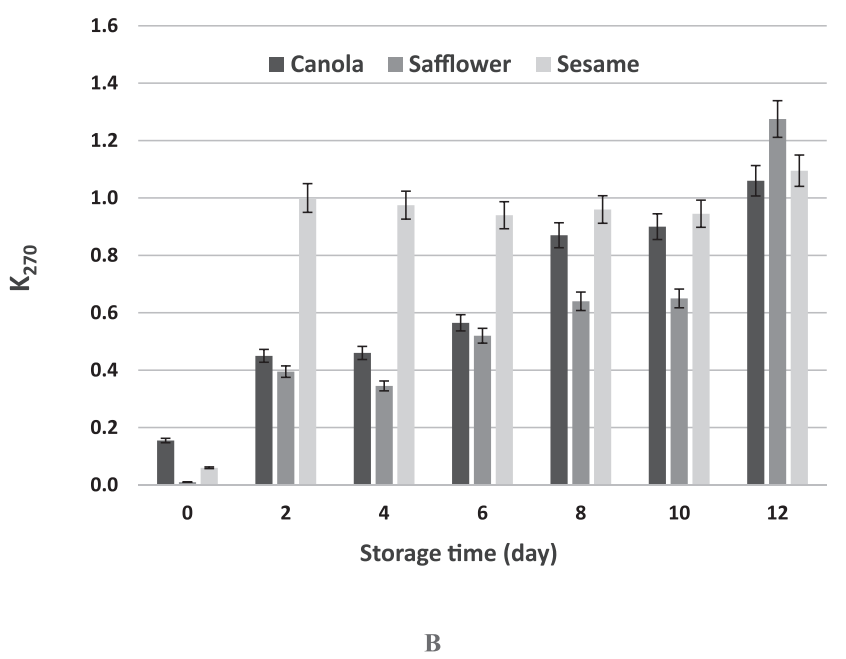

Fig. 1 Changes in $K_{232}$ values (A) and $K_{270}$ values (B) of cold-pressed oils upon heating at $60^{\circ} \mathrm{C}$.

Table 1 Fatty acid composition of cold-pressed oils (relative percentage).

\begin{tabular}{lccc}
\hline \multicolumn{1}{c}{ Fatty acid } & Canola oil & Safflower oil & Sesame oil \\
\hline Myristic, C14:0 & 0.05 & 0.09 & 0.01 \\
Palmitic, C16:0 & 4.78 & 5.62 & 9.79 \\
Palmitoleic, C16:1 & 0.19 & 0.11 & 0.16 \\
Heptadecanoic, C17:0 & 0.03 & 0.03 & 0.03 \\
Heptadecenoic, C17:1 & 0.02 & 0.03 & 0.02 \\
Stearic, C18:0 & 1.59 & 1.84 & 4.86 \\
Oleic, C18:1 & 61.78 & 41.49 & 38.12 \\
Linoleic, C18:2 & 21.72 & 49.93 & 45.99 \\
Linolenic, C18:3 & 8.04 & 0.07 & 0.37 \\
Arachidic, C20:0 & 0.45 & 0.32 & 0.45 \\
Eicosenoic, C20:1 & 1.02 & 0.15 & 0.11 \\
Eicosadienoic, C20:2 & 0.15 & 0.21 & 0.05 \\
Lignoceric, C24:0 & 0.17 & 0.10 & 0.04 \\
\hline
\end{tabular}




\section{Kiralan and M. F. Ramadan}

were similar to those observed in cold-pressed canola oil ${ }^{23)}$. The CD and CT values of sesame and safflower oils were lower than that of sesame oil from Macedonia ${ }^{24)}$ and also that of sesame and safflower oils ${ }^{25)}$.

A few research associated with storage of cold-pressed oils have been reported in the literature. Abuzaytoun and Shahidi ${ }^{26)}$ showed upward tendency for CD value of coldpressed hempseed oil and flaxseed oil upon heating. Khan and Shahidi ${ }^{27)}$ reported that CD value of cold-pressed borage oil reached a maximum value of 20.1 at $60^{\circ} \mathrm{C}$ for 120 $\mathrm{h}$ and kept this value for $168 \mathrm{~h}$. There was no direct comparison between our data with these mentioned literatures because of the differences of oils and analysis method used in these works. These literature indicated that these differences on CD values among the oils were associated with fatty acid composition especially unsaturated fatty acids. A rapid increase trend for $\mathrm{CD}$ values of oil samples observed during storage under oven test condition $\left(60^{\circ} \mathrm{C}\right)$ might be because of unsaturated fatty acid composition especially linolenic and linoleic acids which are rapidly oxidized at these conditions. In our study, safflower oil has higher linoleic acid content among the oil samples.

The evolution of the volatile compounds during oven test $\left(60^{\circ} \mathrm{C}\right)$ is presented in Table 2 . The major identified and analyzed aldehydes were hexanal, 2-heptenal and 2,4-heptadienal isomers for canola oil, as well as hexanal and 2-heptenal for safflower and sesame oil. The major volatile compounds were found as aldehydes during thermal oxidation. Hexanal arises from linoleic acid and is a good indicator for lipid oxidation. Hexanal content of canola, safflower and sesame oil increased up to $6.03,12.05$, and $6.27 \times 10^{6}$ $\mathrm{AU}$ at the end of storage, respectively. (E)-2-heptenal is well known and important volatile aldehyde induced during linoleic acid oxidation wherein the odor threshold of this compound is very low with $0.001 \mathrm{mg} / \mathrm{kg}^{28)}$. The content of this compound in canola, safflower and sesame oil increased to 8.03, 27.10 and $2.30 \times 10^{6} \mathrm{AU}$ at the end of storage, respectively. 2,4-heptadienal isomers were not identified according to the isomer structure. 2,4-heptadienal isomers were only detected in canola oil. The first isomer identified at initial time of experiment and the content of the first isomer increased with increasing thermal oxidation time. The second isomer induced in canola oil after 8 days of storage and its content increased with oxidation time.

Jelen et $a l .{ }^{29)}$ stated that hexanal was the most abundant volatile oxidation compound in fresh cold-pressed oil and also pointed out that 2-heptenal was the major volatile aldehyde after 10 days storage at $60^{\circ} \mathrm{C}$. Torres et al. ${ }^{30)}$ reported that major volatile compounds were hexanal, 2-heptenal, 2,4-decadienal, nonanal and 2,4-heptadienal in soybean oil after 10 days storage at $60^{\circ} \mathrm{C}$. Beltrán et $a l .{ }^{31)}$ reported that hexanal, (E)-2-heptenal, (E)-2-octenal, nonanal, (E)-2-nonenal, (E,E)-2,4-nonadienal and $(\mathrm{E}, \mathrm{E})$ -2,4-decadienal were the major aldehydes in almond oils during thermal oxidation at $100^{\circ} \mathrm{C}$. This work also declared that American almond cultivar Butte had the highest content of (E)-2-heptenal, (E)-2-octenal, (E,E)-2,4-decadienal and $(\mathrm{E}, \mathrm{E})$-2,4-nonadienal in comparison with the Spanish almond cultivars during thermal oxidation. This situation could be explained that linoleic acid content of American almond cultivar were higher than the Spanish cultivars.

At the late stages of oxidation experiment, 2-heptenal was determined as the major volatile oxidation product in the oil samples. This observation was monitored in the cold-pressed oil oxidation at $60^{\circ} \mathrm{C}^{29)}$ wherein 2,4-hexadienal isomers took place an important part of the volatile oxidation compounds during oxidation of canola oil. These compounds were identified and their content were richer among the volatile oxidation products during thermal oxidation of soybean oil ${ }^{30)}$ and almond oil ${ }^{31)}$.

Beside to these major aldehydes, nonanal was found in all samples during oxidation. After 10 days of storage at $60^{\circ} \mathrm{C}$, nonanal content reached up to the maximum level in oils. (E)-2-decenal was the other identified aldehyde found in safflower and sesame oils wherein the content of these compounds generally exhibited a rough trend at thermal oxidation conditions. (E)-2-decenal observed in different packaged olive oils under three storage temperatures (15, 30 and $40^{\circ} \mathrm{C}$ ). The similar trend was observed by Kanavouras et $a l .^{24)}$ who reported that the differences in the levels of this compound could be related the form of singlet or triplet oxygen present in oil. (E,Z)-2,4-decadienal was only found in safflower oil and this compound was present in the maximum level at the end of storage. However, (E,E) -2,4-decadienal found in the fresh canola oil and this compound disappeared with thermal oxidation. Besides, this compound was appeared in safflower oil and the content of this compound reached up to the highest level among oils during storage. (E,E)-2,4-decadienal was detected in the oxidized oils (olive, soybean, sunflower, peanut and rapeseed oils) and its content increased in the oils stored for 5 days at $60^{\circ} \mathrm{C}^{32)}$. The note was peculiar to cold-pressed oils and this sensory situation of these oils could be related to the presence of 2,4-decadienal or hexanal ${ }^{33,34)}$. The presence of 2,4-decadienals in our fresh oils could be explained by this expression and also the similar behavior observed in our samples for hexanal during storage. Its content in the oils decreased up to a certain time during oxidation. Heptanal was the last identified aldehyde and appeared only in safflower oil at the end of storage.

6-methyl 5-hepten-2-one was identified in canola oil and its content showed a wavy behavior during oxidation. This behavior for canola oil are not in agreement with the results of Jeleńet $a l .{ }^{35)}$ who reported that this compound increased in refined rapeseed oil with increasing oxidation time at $60^{\circ} \mathrm{C}$. The other identified ketone was 3,5-octadien- 


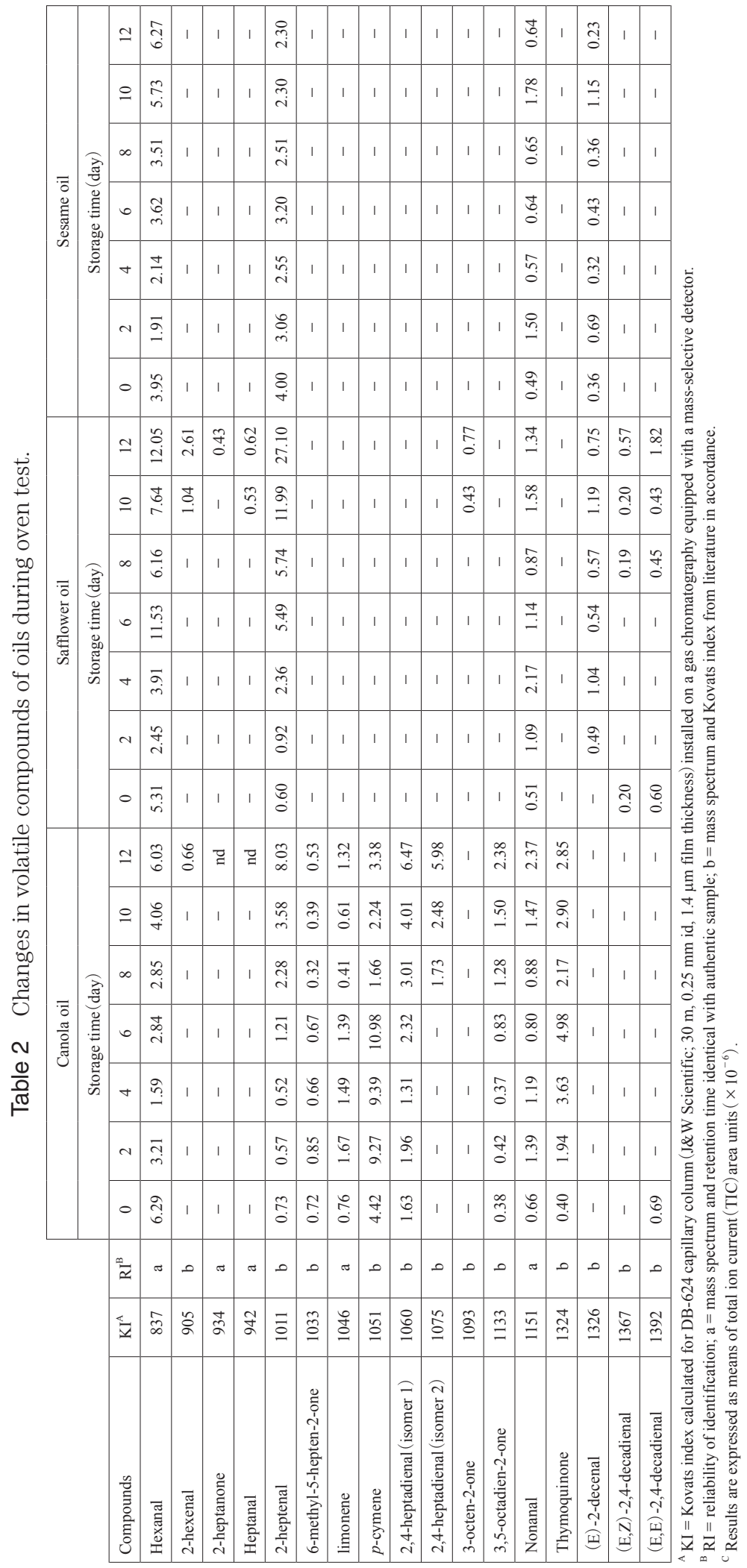




\section{Kiralan and M. F. Ramadan}

2-one which present only in canola oil and its content increased in the oxidized oil during storage. The similar increase trend for canola oil with oxidation was observed in the results of Mildner-Szkudlarz et al. ${ }^{32)}$. 3-octen-2-one and 2-heptanone were found as ketones only in safflower oil at the late of thermal oxidation at $60^{\circ} \mathrm{C}$. These compounds were found in refined and cold-pressed oil treated with conventional heating at $60^{\circ} \mathrm{C}^{29)}$.

The other identified compound group was terpenes including limonene, $p$-cymene and thymoquinone in canola oil. Limonene was found in the volatile fraction of refined and cold-pressed rapeseed oil ${ }^{29)}$. The terpenes were detected in the headspace of sunflower oil and a slightly higher concentrations of these compounds found in the oil samples with different storage conditions (at room temperature in closed receptacles and in the presence of limited amounts of air) as reported by Guillen and Goicoechea ${ }^{1)}$.

\subsection{Microwave treatment}

Figure $2 \mathrm{a}$ shows the changes in $\mathrm{K}_{232}$ values of oil samples during microwave heating. A marked increase was observed in $\mathrm{K}_{232}$ values for all oils treated with microwave. The $\mathrm{K}_{232}$ values of canola, safflower and sesame oils were reached up to 3.01, 4.22 and 4.49, respectively. Regarding $\mathrm{K}_{270}$ values of oil samples, this value for canola and safflower increased gradually but its value for sesame oil raised suddenly from 0 to 2 min of microwave application. $\mathrm{K}_{270}$ values of canola, safflower and sesame oil reached up to 0.64, 0.64 and 1.10, respectively (Fig. 2b).

These results obtained for $\mathrm{K}_{232}$ and $\mathrm{K}_{270}$ values during microwave treatment were in agreement with those obtained by Albi et $a l^{36)}$ who reported that these values in edible oil samples increased and raised up to higher values with increasing the microwave treatment time. They also recorded that the effect of microwave treatment on $\mathrm{K}_{232}$ and $\mathrm{K}_{270}$ values were more efficient than conventional heating in edible oil samples. These results also bear out the observations of Dandjouma et $a l{ }^{37)}$ who reported that the extinction coefficients in Canarium schweinfurthii Engl. oil increased rapidly according to the increase of microwave power and time. These situation could be explained that the effect of microwave energy on radical formation were greater than the effect of conventional heating ${ }^{13)}$.

Regarding the volatile compounds, $p$-cymene was found as the major volatile compound, followed by hexanal in microwave-treated canola oil. 2-heptenal was the other identified aldehyde and increased to the maximum value after 4 min exposure. After 4 min exposure time, 2,4-heptadienal, nonanal and (E,E)-2,4-decadienal were determined among the volatile compounds in canola oil and these aldehydes increased with increasing microwave treatment time. The other identified terpenes were $\alpha$-thujene, limonene, $\gamma$-terpinene and thymoquinone. $\alpha$-thujene and $\gamma$-terpinene were found only in the samples treated with

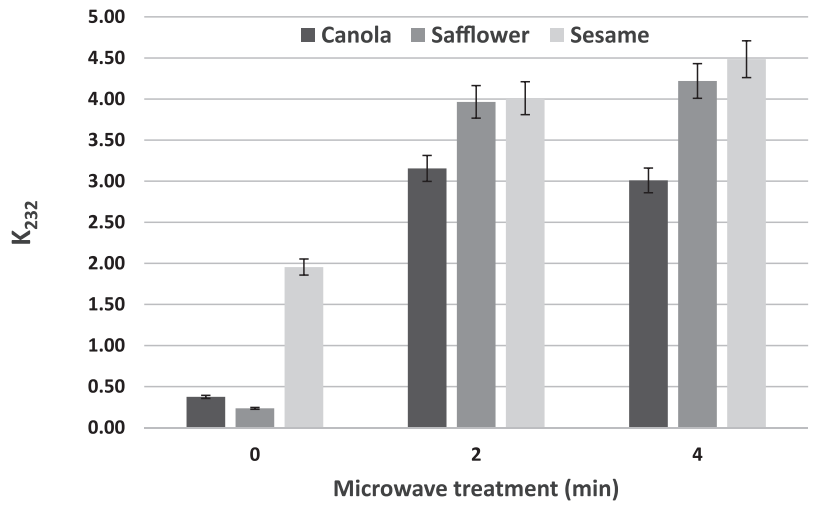

$\mathbf{A}$

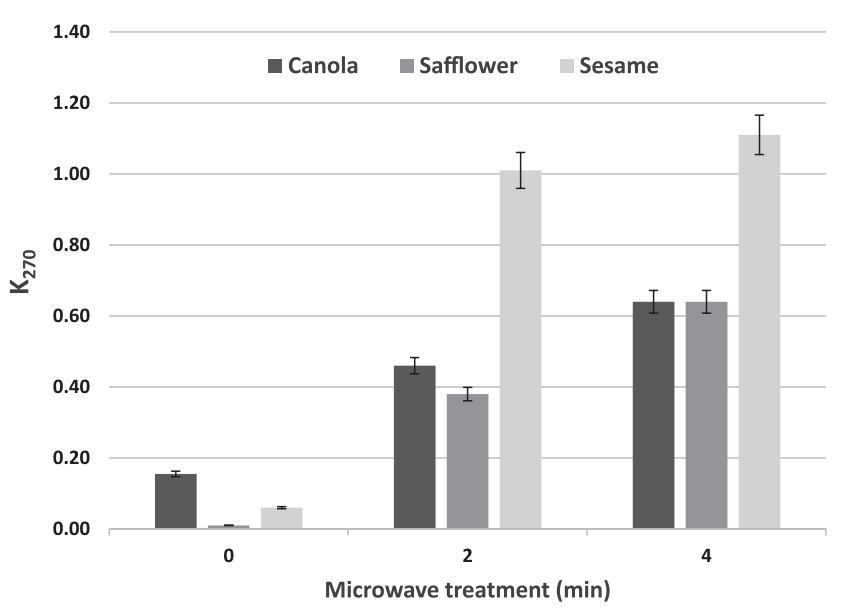

B

Fig. 2 Changes in $\mathrm{K}_{232}$ values $(\mathrm{A})$ and $\mathrm{K}_{270}$ values $(\mathrm{B})$ of cold-pressed oils upon microwave treatment.

microwave compared to ones treated with convectional heating. 6-methyl-5-hepten-2-one disappeared after 4 min exposure time. Higher levels of hexanal and 2-heptenal were found in the oxidized oils upon microwave treatment. Hexanal content increased with the exposure time and 2-heptenal was determined in only one sample after $4 \mathrm{~min}$ application. 2-Hexenal, nonanal, (E,Z)-2,4-decadienal and (E,E)-2,4-decadienal were the other identified volatile compounds and all of them appeared after $4 \mathrm{~min}$. Hexanal and 2-heptenal were the major volatile compounds in sesame oil oxidized with microwave. 2-Hexenal, heptanal, (E)-2-octenal, nonanal, (E)-2-decenal, (E,Z)-2,4-decadienal and (E,E)-2,4-decadienal were the other identified volatile compounds in sesame oil during microwave treatment. $p$-Cymene and $\gamma$-terpinene were found in the sesame oil samples as terpenes. (E)-2-octene is a hydrocarbon found in sesame oil and occured upon microwave treatment.

(E)-2-Decenal, (E)-2-undecenal, (E,E)- and (E,Z) 
Table 3 Changes in volatile compounds of oils as affected by microwave heating.

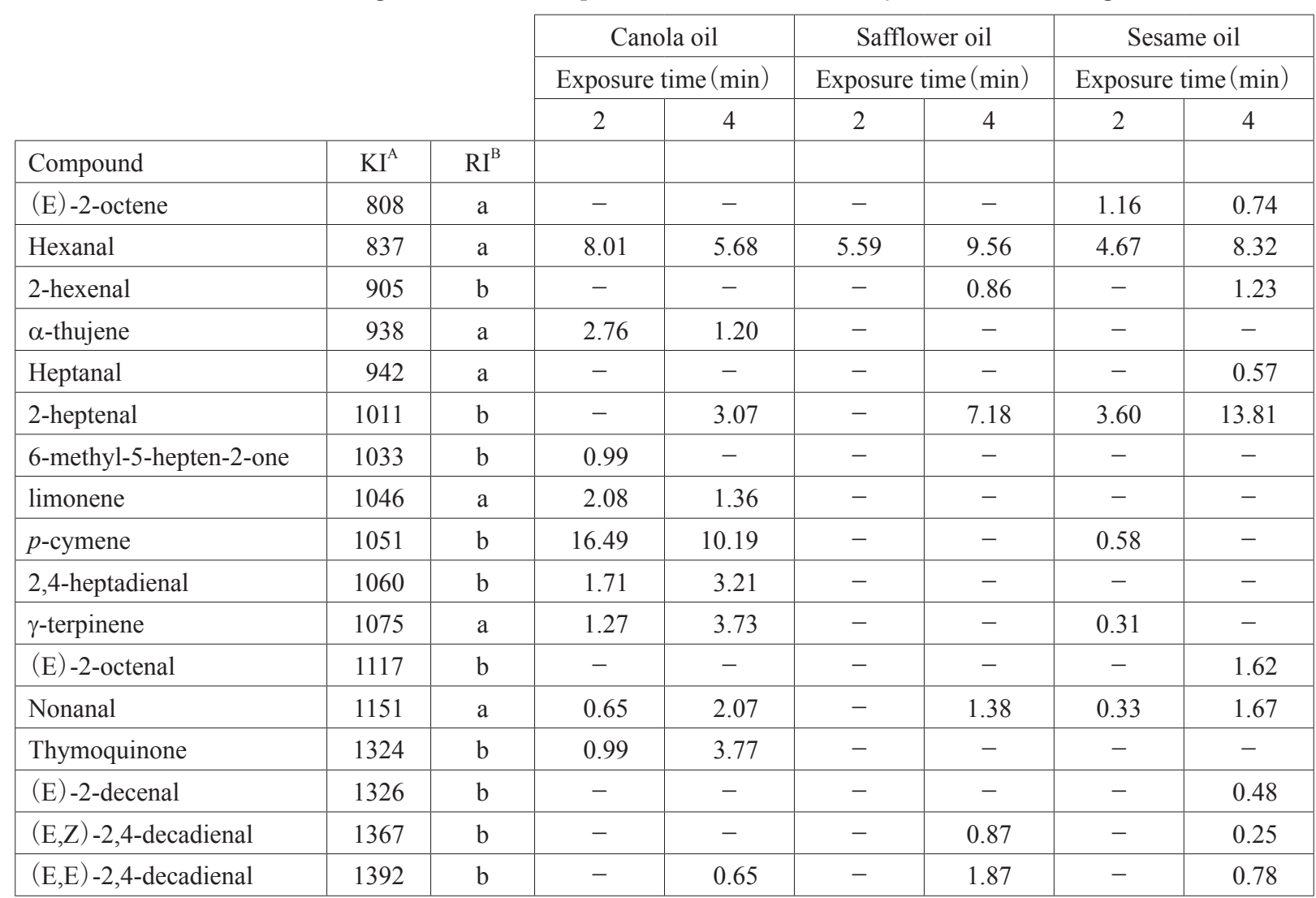

${ }^{\mathrm{A}} \mathrm{KI}=$ Kovats index calculated for DB-624 capillary column (J\&W Scientific; $30 \mathrm{~m}, 0.25 \mathrm{~mm}$ id, $1.4 \mu \mathrm{m}$ film thickness) installed on a gas chromatography equipped with a mass-selective detector.

${ }^{\mathrm{B}} \mathrm{RI}=$ reliability of identification; $\mathrm{a}=$ mass spectrum and retention time identical with authentic sample; $\mathrm{b}=$ mass spectrum and Kovats index from literature in accordance.

${ }^{\mathrm{C}}$ Results are expressed as means of total ion current $(\mathrm{TIC})$ area units $\left(\times 10^{-6}\right)$.

-2,4-decadienal were identified compounds found upon microwave treatment in olive oil. Beside to these aldehydes, pentanal, hexanal, heptanal, (E)-2-hexenal, octanal, (E) -2-heptenal and nonanal were found in oxidized samples ${ }^{38)}$. Some of identified compounds in our oil samples were consistent with the results of Cossignani et al. ${ }^{38)}$. There was no literature information about the effects of microwave treatment on the volatile oxidation compounds of cold-pressed oils, therefore, no comparison could be done with the literatures.

\section{References}

1) Guillen, M. D.; Goicoechea, E. Formation of oxygenated $\alpha, \beta$-unsaturated aldehydes and other toxic compounds in sunflower oil oxidation at room temperature in closed receptacles. Food Chem. 111, 157-164 (2008).

2) Gülçin, İ.; Elmastaş, M.; Aboul-Enein H. Y. Antioxidant activity of clove oil-A powerful antioxidant source.
Arabian J. Chem. 5, 489-499(2012).

3) Göçer, H.; Gülçin, İ. Caffeic acid phenethyl ester (CAPE): Correlation of structure and antioxidant properties. Inter. J. Food Sci. Nutr. 62, 821-825 (2011).

4) Shahidi, F. Natural antioxidants: chemistry, health effects, and applications. The American Oil Chemists Society (1997).

5) Choe, E.; Min, D. B. Mechanisms and factors for edible oil oxidation. Comp. Rev. Food Sci. Food Safety 5, 169-186 (2006).

6) Steenson, D.; Lee, J.; Min, D. Solid phase microextraction of volatile soybean oil and corn oil compounds. $J$. Food Sci. 67, 71-76(2002).

7) Vaisey-Genser, M.; Malcomson, L.; Przybylski, R.; Eskin, N. Consumer acceptance of stored canola oils in canola. $12^{\text {th }}$ Project report research on canola, seed, oil meal. Canada Canola Council. Canada. 189-202 (1999).

8) Cerretani, L.; Bendini, A.; Rodriguez-Estrada, M. T.; Vittadini, E.; Chiavaro, E. Microwave heating of differ- 


\section{Kiralan and M. F. Ramadan}

ent commercial categories of olive oil: Part I. Effect on chemical oxidative stability indices and phenolic compounds. Food Chem. 115, 1381-1388(2009).

9) Sultana, B.; Anwar, F.; Przybylski, R. Antioxidant potential of corncob extracts for stabilization of corn oil subjected to microwave heating. Food Chem. 104, 997-1005 (2007).

10) Lee, Y. C.; Kim, I. H.; Chang, J.; Rhee, Y. K.; Oh, H. I.; Park, H. K. Chemical compositions and oxidative stability of safflower oil prepared with expeller from safflower seeds roasted at different temperatures. $J$. Food Sci. 69, 33-38(2004).

11) Hassanein, M. M.; El-Shami, S. M.; El-Mallah, M. H. Changes occurring in vegetable oils composition due to microwave heating. Grasas y Aceites 54, 343-349 (2003).

12) Anjum, F.; Anwar, F.; Jamil, A.; Iqbal, M. Composition and oxidative stability of sunflower seed oil. J. Amer. Oil Chem. Soc. 83, 770-777(2006).

13) Yoshida, H.; Kajimoto, G. Microwave heating affects composition and oxidative stability of sesame ( $\mathrm{Sesa}$ mum indicum) oil. J. Food Sci. 59, 613-616 (1994).

14) Wei, F.; Yang, M.; Zhou, Q.; Zheng, C.; Peng, J.-H.; Liu, C.-S.; Huang, F.-H.; Chen, H. Varietal and processing effects on the volatile profile of rapeseed oils. LWTFood Sci.Technol. 48, 323-329(2012).

15) Ramadan, M. F. Healthy blends of high linoleic sunflower oil with selected cold pressed oils: Functionality, stability and antioxidative characteristics. Ind. Crop. Prod. 43, 65-72(2013).

16) Ramadan, M. F.; Asker, M. M. S.; Tadros, M. Antiradical and antimicrobial properties of cold-pressed black cumin and cumin oils. Eur. Food Res. Technol. 234, 833-844(2012).

17) Kiralan, M.; Özkanb, G.; Bayrak, A.; Ramadan, M. F. Physicochemical properties and stability of black cumin (Nigella sativa) seed oil as affected by different extraction methods. Ind. Crop. Prod. 57, 52-58 (2014).

18) IUPAC. Standard methods for the analysis of oils, fats and derivatives. International Union of Pure and Applied Chemistry (IUPAC) Method 2.301, Report of IUPAC Working Group WG 2/87Blackwell Scientific Publications, Palo Alto, CA, USA (1987).

19) Firestone, D. (ed.) Official Methods and Recommended Practices of the American Oil Chemists' Society, 4th edn. American Oil Chemists' Society, Champaign (1997).

20) Bauer, B.; Kostik, V.; Gjorgjeska, B. Fatty acid composition of seed oil obtained from different canola varieties. Farmaceutski glasnik 71, 1-7 (2015).

21) Gecgel, U., Demirci, M., Esendal, E., Tasan, M. Fatty acid composition of the oil from developing seeds of different varieties of safflower (Carthamus tinctorius
L.). J. Am. Oil Chem. Soc. 84, 47-54(2007).

22) Uzun, B.; Ulger, S.; Cagirgan, M. Comparison of determinate and indeterminate types of sesame for oil content and fatty acid composition. Turkish J. Agri. For. 26, 269-274 (2002).

23) Teh, S.-S.; Birch, J. Physicochemical and quality characteristics of cold-pressed hemp, flax and canola seed oils. J. Food Comp. Anal. 30, 26-31 (2013).

24) Kanavouras, A.; Hernandez-Münoz, P.; Coutelieris, F.; Selke, S. Oxidation-derived flavor compounds as quality indicators for packaged olive oil. J. Am. Oil Chem. Soc. 81, 251-257(2004).

25) Prescha, A.; Grajzer, M.; Dedyk, M.; Grajeta, H. The antioxidant activity and oxidative stability of coldpressed oils. J. Am. Oil Chem. Soc. 91, 1291-1301 (2014).

26) Abuzaytoun, R.; Shahidi, F. Oxidative stability of flax and hemp oils. J. Am. Oil Chem. Soc. 83, 855-861 (2006).

27) Khan, M. A.; Shahidi, F. Oxidative stability of stripped and nonstripped borage and evening primrose oils and their emulsions in water. J. Am. Oil Chem. Soc. 77, 963-969 (2000).

28) Morales, M.; Luna, G.; Aparicio, R. Comparative study of virgin olive oil sensory defects. Food Chem. 91, 293-301 (2005).

29) Jelen, H. H.; Obuchowska, M.; Zawirska-Wojtasiak, R.; Wasowicz, E. Headspace solid-phase microextraction use for the characterization of volatile compounds in vegetable oils of different sensory quality. J. Agric. Food Chem. 48, 2360-2367 (2000).

30) Torres, M.; Lloret, C.; Sosa, M.; Maestri, D. Composition and oxidative stability of soybean oil in mixtures with jojoba oil. Eur. J. Lipid Sci. Technol. 108, 513520 (2006).

31) Beltrán, A.; Ramos, M.; Grané, N.; Martín, M.; Garrigós, M. Monitoring the oxidation of almond oils by HSSPME-GC-MS and ATR-FTIR: Application of volatile compounds determination to cultivar authenticity. Food Chem. 126, 603-609 (2011).

32) Mildner-Szkudlarz, S.; Jeleń, H. H.; Zawirska-Wojtasiak, R.; Wassowicz, E. Application of headspace-solid phase microextraction and multivariate analysis for plant oils differentiation. Food Chem. 83, 515-522 (2003).

33) Angerosa, F.; Mostallino, R.; Basti, C.; Vito, R. Virgin olive oil odour notes: their relationships with volatile compounds from the lipoxygenase pathway and secoiridoid compounds. Food Chem. 68, 283-287 (2000).

34) Kostadinović Veličkovska, S.; Brühl, L.; Mitrev, S.; Mirhosseini, H.; Matthäus, B. Quality evaluation of cold-pressed edible oils from Macedonia. Eur. J. Lipid Sci. Technol. 117, 2023-2065(2015).

35) Jeleń, H.; Mildner-Szkudlarz, S.; Jasińska, I.; Wąsowicz, 
E. A headspace-SPME-MS method for monitoring rapeseed oil autoxidation. J. Am. Oil Chem. Soc. 84, 509-517 (2007).

36) Albi, T.; Lanzón, A.; Guinda, A.; Pérez-Camino, M.; Leon, M. Microwave and conventional heating effects on some physical and chemical parameters of edible fats. J. Agric. Food Chem. 45, 3000-3003(1997).
37) Dandjouma, A. K. A.; Tchiégang, C.; Kapseu, C.; Fanni, J.; Parmentier, M. Changes in Canarium schweinfurthii Engl. oil quality during microwave heating. Eur. J. Lipid Sci. Technol. 108, 429-433(2006).

38) Cossignani, L.; Simonetti, M. S.; Neri, A.; Damiani, P. Changes in olive oil composition due to microwave heating. J. Am. Oil Chem. Soc. 75, 931-937(1998). 